\title{
Improved Weighted Shapley Value Model for the Fourth Party Logistics Supply Chain Coalition
}

\begin{abstract}
$\mathrm{Na} \mathrm{Xu}$
School of Business, Shandong Jianzhu University, Jinan, Shandong 250101, China

Correspondence should be addressed to Na Xu; xuna_1011@163.com

Received 25 June 2013; Accepted 31 August 2013

Academic Editor: Jason Gu

Copyright (C) $2013 \mathrm{Na} \mathrm{Xu}$. This is an open access article distributed under the Creative Commons Attribution License, which permits unrestricted use, distribution, and reproduction in any medium, provided the original work is properly cited.

How to make the individual get the reasonable and practical profit among the fourth party logistics supply chain coalition system is still a question for further study. Considering the characteristics of the fourth party logistics supply chain coalition, this paper combines Shapley Value with Distribution according to Contribution, two methods in the application, and then adjusts the profit allocated to each member reasonably based on the actual coalition situation named improved weighted Shapley Value model. In this paper, we first analyze the fourth party logistics supply chain coalition profit allocation models, the classical Shapley value method. Then, we analyze the weight of individual enterprise in the coalition by the analytic hierarchy process. To each enterprise, the weight is determined by the investment risks, information divulging risks, and failure risks. Finally, the numerical study shows that the profit allocation method improved weighted Shapley value model is relatively rational and practical. Thus, the proposed combined model is a useful profit allocation mechanism for the fourth party logistics supply chain coalition that the contribution and risks are fully considered.
\end{abstract}

\section{Introduction}

"The fourth party logistics (4PL) [1] is Supply Chain Integrated Provider, which integrate and manage the different resources, abilities and technologies belonging to the company's complementary service provider, and provide the overall solution to the supply chain with the customers." [2].

In this paper the fourth party logistics [3] particularly refers to the logistics and supply chain operation mode.

The fourth party logistics delivers supply chain service outsourcing to the fourth party, makes programs about the solutions to the supply chain management, and is responsible for the feedback of the supervision and management of solutions to supply chain management. Supply chain begins with the procurement of raw materials, and then, it produces intermediate products and final products and finally delivers products to consumers by sales system. It is the functional chain structure model consisting of manufacturers, distributors, retailers, and consumers.

The fourth party logistics supply chain refers to that the fourth party logistics service providers integrate and coordinate different types of resources, capabilities, and technologies belonging to competitive and complementary enterprises as shown in Figure 1. Its purpose is to integrate and optimize all the resources, technologies, and abilities of the enterprises in the coalition of the supply chain system. All these enterprises include suppliers, manufacturers, distributors, transporters, and warehousing and storage which are called logistics service providers and other auxiliary organizations. The fourth party logistics service providers play the roles of the builder and coordinator.

Risks arise when the fourth party logistics supply chain operates, because of the unpredicted effects brought by the unconfirmed factors of the inner and outside environment. The deviation between actual profit and expected profit and the possibility of the loss of the individual enterprise in the coalition can be enlarged [1-4].

The fourth party logistics supply chain risk management refers to identifying the risks existing when the supply chain operates, analyzing the mechanism, evaluating the effect, controlling and regulating all the risks by taking appropriate measures, and then enhancing the reliability of the supply chain operation through coalition among enterprises. 


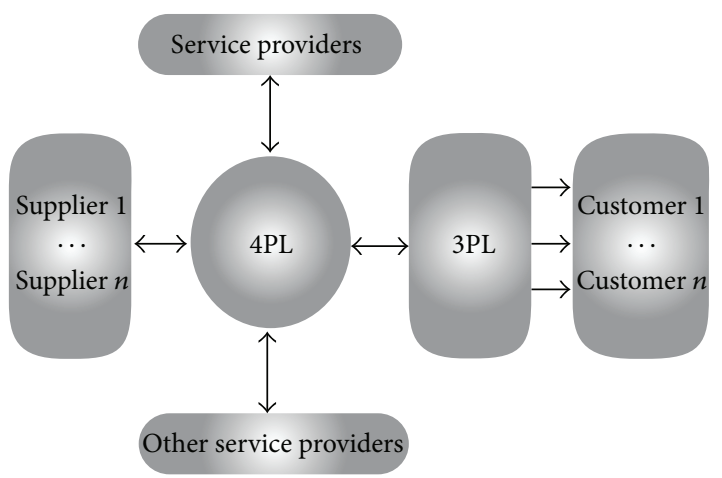

FIgURE 1: The fourth party logistics supply chain coalition.

The core enterprise of the supply chain knows the requirements of the market and coordinates with the other partners, and all the enterprises work together to make optima performance to improve the supply chain competiveness. The individual enterprise makes the individual profit maximum as well as the whole through the coalition. How to allocate profit rationally is determined by the contribution weight consisting of investment risks, information divulging risks, and information divulging risks.

Tanimoto has built models of the mechanism of cost allocation by the agents. The coalition and the rule of the cost allocation will be realized under the cost structure [5]. Moreover, Skorin-Kapov has suggested further analysis of the multicasting cost allocation problem using the modified multicasting game [6]. Also Chen et al. have studied the ratio of profit allocation based on the evolution game theory [7] and cooperative game theory [8].

A multiagent system model and game theory and Nash equilibrium algorithms based on market competition have been proposed for task allocation [9]. The supply chain profit has been allocated by using the risk-considered Shapley value method [10] and cooperation game theory [11-13]. Wang and Zhou have built profit allocation model of three-stage supply chain with multidirectional and principal subordinate [14].

The rest of the paper has been organized as follows: Section 2 states the problem of statement. Sections 3 and 4 propose the model and algorithm for profit allocation in the fourth party logistics supply chain coalition. A numerical study has been included in Section 5, and the last section concludes the paper.

\section{Description of Problem}

The relationship among member enterprises in the fourth party logistics supply chain coalition is a strategic collaboration partnership and in essence a competitive relationship based on cooperation. Based on the cooperation when the upstream and downstream enterprises compete with each other for the resources (including power resources) and thus enjoy the greater profits, the characteristics of the competitiveness exist.

When the member enterprises with the same level compete with each other for the orders, the characteristics of the competitiveness also exist. The relationship among member enterprises in the fourth party logistics supply chain coalition is collaborated. The member enterprises are not allowed to manage or to be managed. The member enterprises have their own decision power. The fourth party logistics service providers make suggestions for the work and profit allocation among the member enterprises according to the overall situation, then supervise the performing of the contract, and take punishment measures for breach of contracts. So the mode of the fourth party logistics supply chain coalition is mixed with the integration and separation [15].

The profit allocation is the major problem in the fourth party logistics supply chain coalition. Thus, how to allocate profit allocation rationally and practically among the member enterprises is the problem discussed in the paper.

The allocation of profits reasonably among the fourth party logistics supply chain coalition is the main objective of this paper.

\section{Coalition Game}

The main problem of the fourth party logistics supply chain coalition game is how to allocate the total output and utility reasonably. Thus, all the individuals can get the profit belonging to them.

Given the finite set $N$, coalition game is defined as $G=$ $(N, V)$. Characteristic function $v$ is the reflection from $2^{N}=$ $\{S \mid S \subseteq N\}$ to real number set $R^{N}, v: 2^{N} \rightarrow R^{N}, v(\phi)=0$ :

$$
\begin{gathered}
v(S)=\sum_{i \in S} c(\{i\})-c(S), \quad \forall S(S \subseteq N), \\
v(\phi)=0 .
\end{gathered}
$$

\section{Profit Allocation Model}

4.1. Shapley Value. Shapley Value is the classical method in the profit allocation and reflects the importance of the individuals among the fourth party logistics supply chain coalition enterprises according to the ratio of the valueadded profit allocation. Shapley Value can be explained as the average marginal contribution in which each individual would make it to the grand coalition if it were to form an individual a time. Mathematically, Shapley Value is expressed as

$$
\begin{aligned}
y_{i} & =\phi_{i}(v) \\
& =\sum_{i \in S} \frac{(n-s) !(s-1) !}{n !}(v(S)-v(S \backslash\{i\})), \quad \forall i \in N,
\end{aligned}
$$

where $s$ denotes the number of carriers in coalition $S$.

Shapley Value profit allocation method assumes the contribution among the enterprises in the alliance, not considering the risk factors, and so forth, in the allocation. Now the research about the improved Shapley Value based on the individual difference has been developed. Considering 


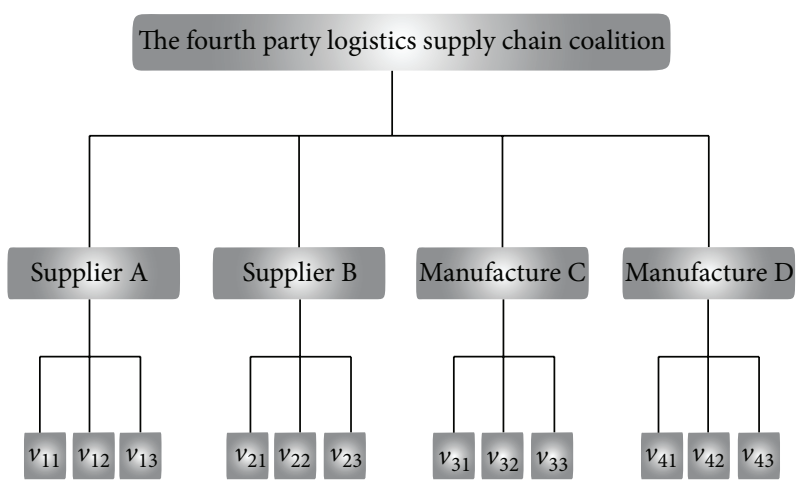

Figure 2: The hierarchical structure model.

the investment risks, information divulging risks, and failure risks, the different contribution among the coalition enterprises is different. So, we have been revising Shapley Value method [16-21].

The individual profit allocated by Shapley Value among the fourth party logistics supply chain coalition cannot be allocated according to the actual contribution and risks factors. So, we adjust the Shapley Value to make it apply to the actual situation and applications.

4.2. Distribution according to Contribution. Before we assume the contribution (including the risks) among the fourth party logistics supply chain coalition enterprises we should assume $p_{i} . P_{i}$ denotes the weight of the importance of the coalition enterprises. To each coalition enterprise, the contribution weight is determined by the investment risks $v_{i 1}$, information divulging risks $v_{i 2}$, and failure risks $v_{i 3}$.

$P_{i}$ is determined by analytic hierarchy process (AHP). AHP is an effective and mature method. It can be used to deal with the complex relationships by quantitative analysis method. First, we decompose the complex relationship to different indexes, then make hierarchical structure diagrams according to the relationship, and finally build the judgment matrix according to the relative importance of the different layer indexes.

Here, we make the hierarchical structure model of the fourth party logistics supply chain coalition including object layer, rule layer, and schemes layer as shown in Figure 2.

We build the judgment matrix as shown in Table 1 according to the importance between the upper and lower layer on the basis of the hierarchical structure model. We adopt the 1-9 scale method by Professor Saaty. Among them 1 denotes the one that is as important as the other, 3 denotes the one that is slightly important than the other, 5 denotes the one that is much more important than the other, 7 denotes the one that is extremely important than the other, 9 denotes the one that is entirely important than the other [22-24], and $x_{i}$ denotes the individual enterprise among the coalition.

According to the judgment matrix, we calculate the weight of the fourth logistics supply chain coalition enterprises by the square root method.

We first calculate the product of each row elements of the judgment matrix named $M_{i}=\prod_{j=1}^{n} x_{i j}$, then calculate
TABLE 1: Judgement matrix.

\begin{tabular}{lcccc}
\hline $\begin{array}{l}\text { The fourth party logistics } \\
\text { supply chain coalition } \\
\text { enterprises }\end{array}$ & $x_{1}$ & $x_{2}$ & $x_{3}$ & $x_{4}$ \\
\hline$x_{1}$ & 1 & 7 & 3 & 5 \\
$x_{2}$ & $1 / 7$ & 1 & $1 / 6$ & $1 / 2$ \\
$x_{3}$ & $1 / 3$ & 6 & 1 & 4 \\
$x_{4}$ & $1 / 5$ & 2 & $1 / 4$ & 1 \\
\hline
\end{tabular}

TABLE 2: Weight of coalition.

\begin{tabular}{lc}
\hline $\begin{array}{l}\text { The fourth party logistics supply } \\
\text { chain coalition enterprises }\end{array}$ & Weight \\
\hline$p_{1}$ & 0.56 \\
$p_{2}$ & 0.057 \\
$p_{3}$ & 0.29 \\
$p_{4}$ & 0.097 \\
\hline
\end{tabular}

the $n$th root of $M_{i}$ named $p_{i}=\sqrt[n]{M_{i}}$, and finally normalize to calculate the weight of the fourth logistics supply chain coalition enterprises named

$$
p_{i}=\frac{w_{i}}{\sum_{j=1}^{n} w_{j}}
$$

Because we cannot assure the complete consistency of the judgment matrix when the elements are compared with each other, we need to verify the complete consistency. Calculate

$$
\lambda_{\max }=\frac{1}{n}\left(\sum_{i=1}^{n} \frac{\sum_{j=1}^{n} x_{i j} p_{j}}{p_{i}}\right)=4.13,
$$

where $\lambda_{\max }$ is the biggest characteristic value of the judgment matrix. The consistency index value is $\mathrm{CI}=\left(\lambda_{\max }-n\right) /(n-$ $1)=0.042$. Random consistency ratio is $\mathrm{CR}=\mathrm{CI} / \mathrm{RI}<0.1$. The average random consistency index RI is 0.89 when the order number is 4 . Because $\mathrm{CR}<0.1$, it is in accordance with random consistency.

\section{Analysis}

Now we have the fourth party logistics supply chain coalition which has two suppliers and two manufacturers named $l_{i}$. We use the Shapley Value and the distribution according to the contribution for the fourth party logistics supply chain coalition.

Data of the operation cost and profit of individual enterprises independent operation are shown as follows. (The test data is from a company.)

There are four enterprises in the fourth party logistics supply chain coalition. We calculate the cost and profit after the coalition. We get cost savings of coalition using (1). We analyze the weight of the enterprises in the fourth party logistics supply chain coalition as shown in Table 2.

We use vector (enterprises, profit, cost, and contribution to coalition) to show the instance. 
The data can be expressed by vector (enterprises, profit, cost, and contribution to coalition).

The data is shown as follows:

$$
\begin{aligned}
& \left(x_{1}, 0,5603.7,26557.6\right)\left(x_{2}, 0,4156.9,19197.6\right) \\
& \left(x_{3}, 0,4598.4,24976.6\right)\left(x_{4}, 0,5406.9,19909.6\right) \\
& \left(x_{1} x_{2}, 1216.7,8543.9,0\right)\left(x_{1} x_{3}, 1768.3,8433.8,0\right) \\
& \left(x_{1} x_{4}, 1174.0,9836.6,0\right)\left(x_{2} x_{3}, 975.3,7780,0\right) \\
& \left(x_{2} x_{4}, 629.7,8934.1,0\right)\left(x_{3} x_{4}, 1516.9,8488.4,0\right) \\
& \left(x_{1} x_{2} x_{3}, 2770.6,11588.4,0\right) \\
& \left(x_{1} x_{2} x_{4}, 2772.9,12394.6,0\right) \\
& \left(x_{1} x_{3} x_{4}, 3123.6,12485.4,0\right) \\
& \left(x_{2} x_{3} x_{4}, 2881.1,11281.1,0\right) \\
& \left(x_{1} x_{2} x_{3} x_{4}, 4527.5,15238.4,0\right) .
\end{aligned}
$$

We calculate the weight using (3):

$$
\left(p_{1}, p_{2}, p_{3}, p_{4}\right)=(0.56,0.057,0.29,0.097) \text {. }
$$

The profit allocated to each individual in the fourth party logistics supply chain coalition that can be calculated using the Shapley Value Equation (2) is shown as follows:

$$
\left(\begin{array}{llll}
x_{1} & x_{2} & x_{3} & x_{4}
\end{array}\right)=(1122.45,916.57,1272.43,1118.22) .
$$

The profit allocated to each individual in the coalition can be calculated using Distribution according to Contribution and is shown as follows:

$$
\left(\begin{array}{llll}
x_{1} & x_{2} & x_{3} & x_{4}
\end{array}\right)=(2480.6,252.5,1284.6,429.7) .
$$

In conclusion, we can see that individual $\mathrm{C}$ gets the maximum profit according to Shapley Value while individual A gets the maximum profit according to Distribution according to Contribution and adjusts the two individuals $\mathrm{AC}$ which get the maximum profits and adjust the individuals $\mathrm{BD}$ reasonably in the same way. The value should be adjusted in accordance with the needs of the coalition in order to make the coalition stronger and better. We should combine the two methods named the improved weighted Shapley Value model for the practical use.

\section{Conclusion}

First of all, we introduce the fourth party logistics and the fourth party logistics supply chain coalition. How to make profit allocation practically and reasonably among the coalition is still a question for further study. We can also call this problem the fourth party logistics supply chain coalition game.

Besides, we introduce the classical method, Shapley Value. We consider the investment risks, information divulging risks and failure risks besides the only contribution. On the basis of the risks, we analyze the weight of the importance of individuals in the coalition by the analytic hierarchy process. To each enterprise, the weight is determined by the investment risks, information divulging risks, and failure risks. We calculate the weight of the fourth party logistics supply chain and assure the complete consistency of the judgment matrix when the elements are compared with each other.

Finally, we analyze the results using Shapley Value and the Distribution according to Contribution. We find that we should combine the two methods for the practical use. The value should be adjusted in accordance with the needs of the coalition in order to make the coalition stronger and better.

We also need further improvement of the two combined methods named the improved weighted Shaplye Value model. We also need further study of how much profit to adjust which is allocated by Shapley Value and contribution weight (including the risks) based on the actual situation.

\section{Conflict of Interests}

The author declares that there is no conflict of interests regarding the publication of this paper.

\section{Acknowledgment}

This work is sponsored in part by a grant from the National Science Foundation (NSF) (project Grant no. 61202363).

\section{References}

[1] Y. Peng, The research of the fourth logistics supply chain management [Ph.D. thesis], Tianjin University, Tianjin, China, 2006.

[2] C. Liu, Fourth party logistics optimization automotive supply chain logistics [M.S. thesis], Jilin University, Jilin, China, 2009.

[3] Q. Zhu and R. Y. K. Fung, Design and Analysis of Optimal Incentive Contracts between Fourth-Party and Third-Party Logistics Providers, System Engineering and Engineering Management, City University of Hong Kong, Hong Kong, 2012.

[4] D. Wang, The research of supplier selection and profit allocation under supply chain risk [Ph.D. thesis], Dalian Maritime University, Liaoning, China, 2007.

[5] K. Tanimoto, "Bargaining over cost allocation rule under uncertainty of project cost," in Proceedings of the 2001 IEEE International Conference on Systems, Man, and Cybernetics, pp. 12701275, 2001.

[6] D. Skorin-Kapov, "On primal-dual cost allocation schema in multicast communication: combinatorial game theory model," in Proceedings of the IEEE 17Th International Conference on Industrial Engineering and Engineering Management (IE\&EM '10), pp. 433-438, 2010.

[7] Z. Chen, S. Yang, and Y. Cao, "Profit allocation in mobile commerce value chain based on the evolution game theory," in Proceedings of the 2nd IEEE International Conference on Information and Financial Engineering (ICIFE '10), pp. 296-300, 2010.

[8] E. Semsar-Kazerooni and K. Khorasani, "A game theory approach to multi-agent team cooperation," in Proceedings of the American Control Conference, pp. 4512-4518, 2009.

[9] G. Wang, H. Yu, J. Xu, and S. Huang, "A multi-agent model based on market competition for task allocation: a game theory approach," in Proceedings of the IEEE International Conference on Networking, Sensing and Control, pp. 282-286, 2004. 
[10] R. Sui and F. Li, "Risk-considered Shapley profit allocation of innovative supply chain," in Proceedings of the IEEE International Conference on Emergency Management and Management Sciences (ICEMMS '10), pp. 238-241, 2010.

[11] L. Chen, M. Shen, and C. Chen, "A research in supply chain profit allocation based on cooperation game theory," in Proceedings of the International Conference on System Science, Engineering Design and Manufacturing Informatization (ICSEM '10), pp. 209-212, 2010.

[12] N. Matsubayashi, M. Umezawa, Y. Masuda, and H. Nishino, "A cost allocation problem arising in Hub-Spoke network systems," European Journal of Operational Research, vol. 160, no. 3, pp. 821-838, 2005.

[13] D. J. Wan, Y. Liu, and B. Yao, "Research on cost allocation in the cooperative game of overflowing infrastructure investment," in Proceedings of the International Conference on Management Science and Engineering, pp. 393-398, 2007.

[14] L. Wang and Y. Zhou, "Research on cooperation profit allocation in three-stage supply chain based on distribution channel," in Proceedings of the 4th International Conference on Wireless Communications, Networking and Mobile Computing, pp. 1-6, 2008.

[15] H. Goudarzi and M. Pedram, "Maximizing profit in cloud computing system via resource allocation," in Proceedings of the International Conference on Distributed Computing Systems Workshops, pp. 3-4, University of Southern California, 2011.

[16] H. Cheng and G. Yang, "A study on profit allocation model based on integrated supply," in Proceedings of the International Conference on Services Systems and Services Management (ICSSSM '05), pp. 613-616, June 2005.

[17] S. Wang and B. Zhao, "Study on profit allocation among green supply chain based on the optimized shapely value," in Proceedings of the 3rd International Conference on Information Management, Innovation Management and Industrial Engineering (ICIII '10), pp. 252-255, November 2010.

[18] N. Matsubayashi, M. Umezawa, Y. Masuda, and H. Nishino, "A cost allocation problem arising in hub-spoke network systems," European Journal of Operational Research, vol. 160, no. 3, pp. 821-838, 2005.

[19] G. Owen, "On the core of linear production games," Mathematical Programming, vol. 9, no. 1, pp. 358-370, 1975.

[20] L. S. Shapley, "A value for n-person games," Annals of Mathematical Studies, vol. 28, pp. 307-317, 1953.

[21] H. P. Young, "Cost allocation: methods, principles, applications," European Journal of Operational Research, vol. 27, no. 2, pp. 254-255, 1986.

[22] L. Saaty, The Analytic Hierarchy Process, McGraw-Hill Company, New York, NY, USA, 1980.

[23] L. Yi, Study on local fiscal risk and its measure to keep a way in China [Ph.D. thesis], Chongqing University, Chongqing, China, 2005.

[24] H. Yuan, "The construction and empirical analysis of nonparametric early-warning system of fiscal risk based on risk factor method and AHP," Journal of Hebei University of Economics and Business, vol. 6, pp. 5-8, 2011. 

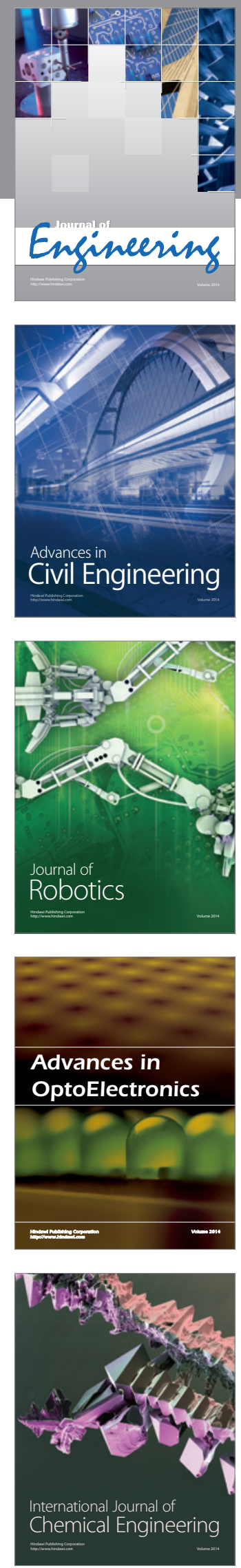

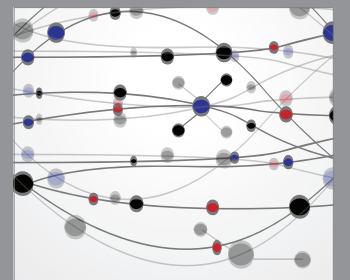

The Scientific World Journal
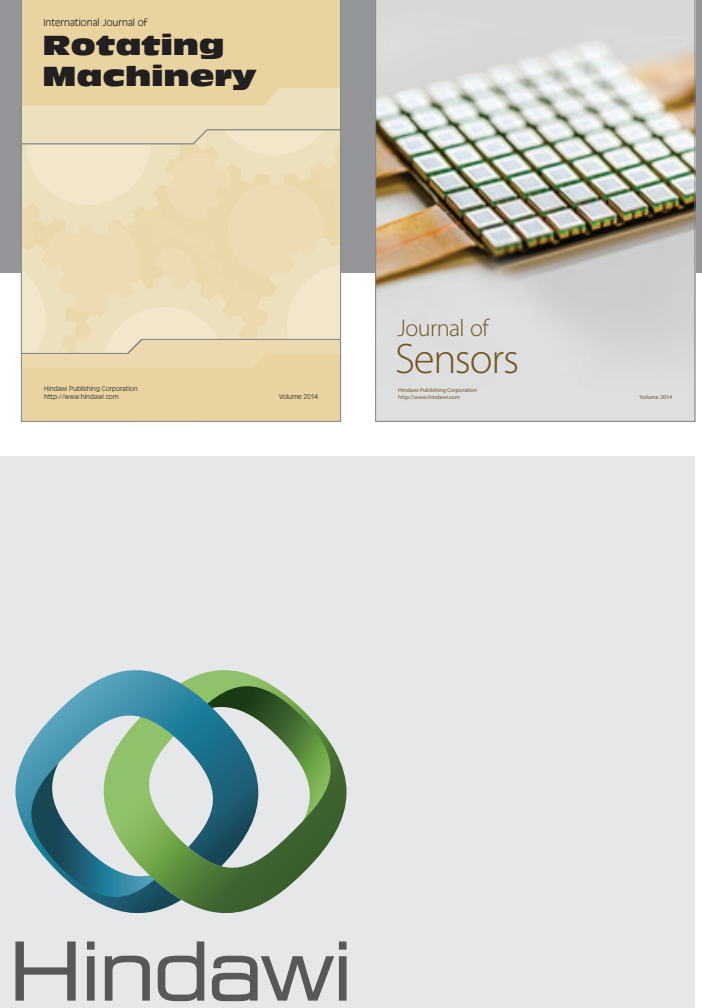

Submit your manuscripts at http://www.hindawi.com
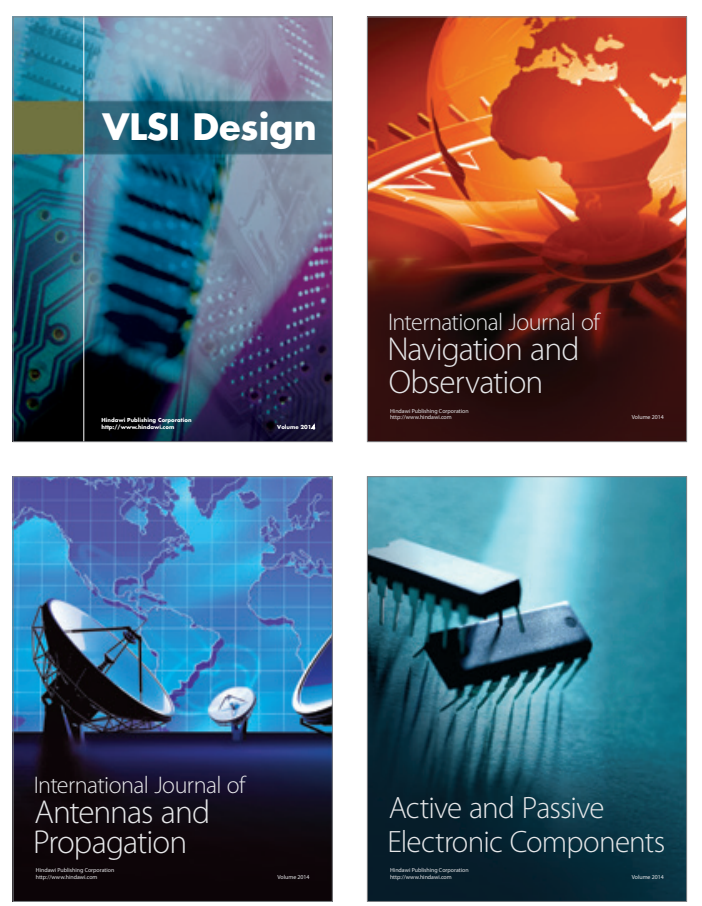
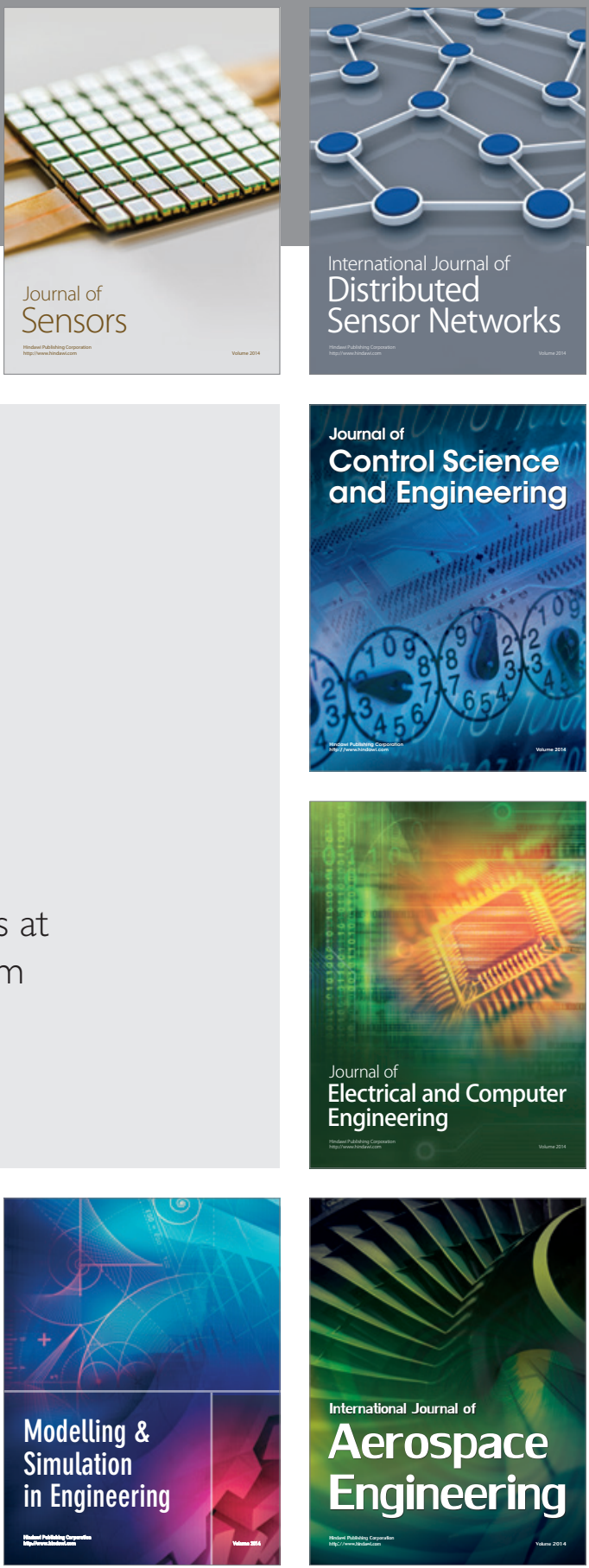

Journal of

Control Science

and Engineering
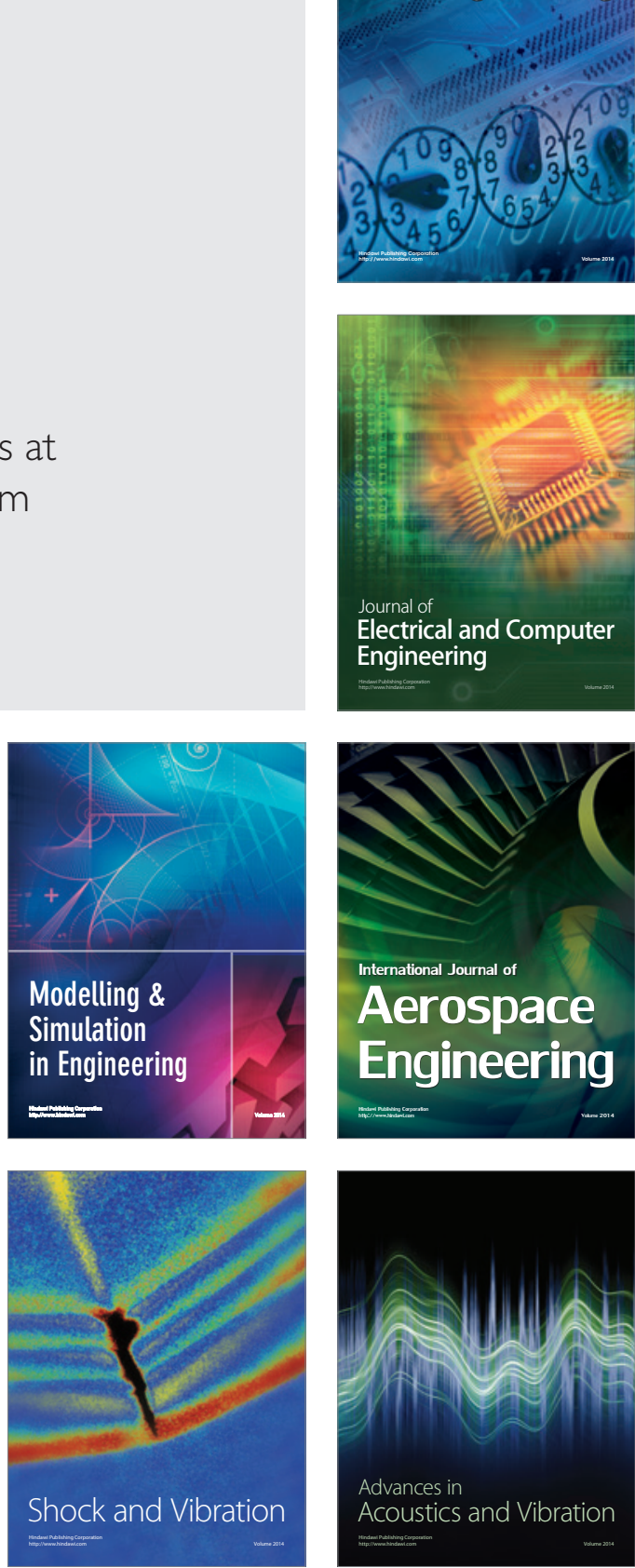